\title{
Adjudicating Death: Professionals or Politicians?
}

\author{
Stephen J. Choi \& Mitu Gulati*
}

INTRODUCTION............................................................ 1709

I. BACKGROUND ....................................................... 1716

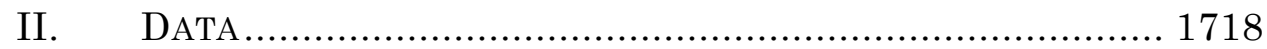

III. ANALYSIS ......................................................... 1721

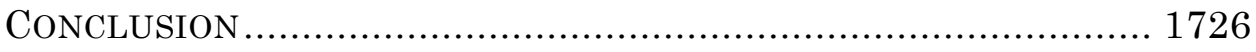

\section{INTRODUCTION}

On February 13, 2016, Justice Antonin Scalia was found dead in his room at a ranch in West Texas, where he was on a hunting vacation, with a pillow over his head. ${ }^{1}$ It is possible that people die with pillows over their heads, but this was the most famous member of the U.S. Supreme Court, who was in good enough health to go on a hunting vacation and had shown few signs of illness to his hunting companions. That said, Justice Scalia was in his late seventies and had the kinds of preexisting medical conditions that made it probable that he had died of natural causes. Nevertheless, there was enough in the story to get conspiracy theorists riled up, and even our current President (then, candidate) said in response to an interviewer asking him about the possibility of something suspicious: "It's a horrible topic, but they say

\footnotetext{
* Faculty at the law schools of NYU and Duke, respectively. For comments on multiple stages of this project, we are grateful to Joe Boatwright, Cindy Gardner, Tracey George, and Un Kyung Park. Katherine Boyles provided exceptional research assistance on a topic where the research material was hard to come by.

1. See Nora Kelly, Why Wasn't Antonin Scalia Given an Autopsy?, Atlantic (Feb. 17, 2016), https://www.theatlantic.com/politics/archive/2016/02/antonin-scalia-autopsy/463251/

[https://perma.cc/YZ52-FN2L] (highlighting the initial uncertainty regarding the placement of a pillow near Scalia's head); Judy Melinek, Justice Scalia's Unexamined Death Points to a Problem, CNN (Feb. 20, 2016, 9:38 PM), http://www.cnn.com/2016/02/18/opinions/justice-scalia-no-autopsymelinek/index.html [https://perma.cc/V32H-V5C8] (examining issues with the current system of death investigation).
} 
they found a pillow on his face, which is a pretty unusual place to find a pillow."2

Yet, the death examiner, Cinderela Guevara-not a trained pathologist, but a local county judge-decided to forego the autopsy without visiting the scene because the county sheriff assured her that there was "no foul play," Justice Scalia's personal physician told the judge that the death was due to "natural causes," and the Scalia family requested that no autopsy take place. ${ }^{3} \mathrm{Had}$, by contrast, Justice Scalia died in a hotel in Boston, Singapore, or Tokyo, there would have been a detailed investigation and an autopsy by a qualified pathologist. ${ }^{4}$ That is, the kind of examination that those of us who watch crime shows on television assume happens in every case.

Putting aside the credibility of Alex Jones and other conspiracy theorists about whether President Obama or aliens were eliminating conservative Supreme Court Justices prior to the 2016 presidential election, ${ }^{5}$ there exists a real question here, which is whether there needs to be a uniform system of professional death examinations across the United States. Currently, there are counties and states where decisions about autopsies and the issuance of death certificates are made by a local coroner who often needs nothing more than a high school diploma to run for election to the job of coroner. ${ }^{6}$ In the nineteenth century, the coroner system predominated in the United States. Many but not all states shifted toward professional medical examiners in the twentieth

2. See Gideon Resnick, Meet the Scalia Death Truthers: Was He Murdered by Obama or Aliens?, DAILY BEAST (Feb. 16, 2016, 12:01 AM), http://www.thedailybeast.com/meet-the-scaliadeath-truthers-was-he-murdered-by-obama-or-aliens [https://perma.cc/Y9AS-2QAT] (reporting on an interview with President Donald Trump by Michael Savage and on Alex Jones's conspiracy theories on the matter).

3. See Mark Berman, Texas Judge Defends Decision Not to Order Autopsy for Justice Scalia, WASH. POST (Feb. 16, 2016), https://www.washingtonpost.com/news/postnation/wp/2016/02/16/texas-judge-defends-decision-not-to-order-autopsy-for-justice-

scalia/?utm_term=.91b61b0fb9a8 [https://perma.cc/M3VF-BSY9] (discussing criticism and conspiracy resulting from the decision not to perform an autopsy).

4. See Melinek, supra note 1 (discussing the independent death investigations conducted by medical examiner officers in urban areas).

5. See Brian Tashman, Alex Jones: Obama Murdered Justice Scalia and Donald Trump Is Next, Right Wing WATCH (Feb. 14, 2016, 6:15 PM), http://www.rightwingwatch.org/post/alexjones-obama-murdered-justice-scalia-and-donald-trump-is-next/ [https://perma.cc/VD5D-MED6] (detailing conspiracy theory).

6. See Carl Parrott, Advantages and Disadvantages of the Coroner System, in 2003 Medicolegal Death InVEstigation Sys.: Workshop Summary 25, 25, https://www.ncbi.nlm.nih.gov/books/NBK221919/pdf/Bookshelf_NBK221919.pdf

[https://perma.cc/43XP-ALSA] [hereinafter MEDICOLEGAL WoRKSHOP SUMMARY] ("Coroners are elected lay people who often do not have professional training, whereas medical examiners are appointed and have board-certification in a medical specialty.”). See generally JEFFREY M. Jentzen, Death Investigation in America: Coroners, Medical Examiners, and the PuRsuit OF MEDiCAL CERTAINTY (2009) (comparing systems of death investigation in the United States). 
century. Members of the medical profession who work in this area have long expressed concern about the persistence of coroners today in certain states. ${ }^{7}$ For them, the answer is obvious: the system should be run by highly trained, board-certified pathologists. ${ }^{8}$ Our instinct is that the doctors are probably right. Given that there is significant variation across the states in terms of whether death examination offices are run by trained professionals or local politicians, we should, in theory, be able to empirically test the question of whether professionals or politicians do a better job of adjudicating death. It turns out that, although there are strong opinions about what the answer surely is, there has been little in the way of serious empirical work addressing this question. Our Article takes a first cut at looking at how one might do that analysis.

The question of whether professionals or politicians are best suited for a given task is not unique to death examiners. There has, for example, long been a robust debate on the question of whether appointed judges (professionals) are better than elected judges (politicians). Politicians are likely to be more responsive to the immediate needs of the voting public; after all, they want to be reelected. But that also means that they are likely to be less independent. ${ }^{9}$ If they believe that being hard on criminals is a good votegetting strategy, they are likely to do that. Indeed, research suggests

7. E.g., Melinek, supra note 1; see also Randy Hanzlick, The Conversion of Coroner Systems to Medical Examiner Systems in the United States: A Lull in the Action, 28 AM. J. ForENSIC MED. \& PATHOLOGY 279, 279 (2007) (explaining the importance of qualified medical examiners); Randy Hanzlick \& Debra Combs, Medical Examiner and Coroner Systems: History and Trends, $279 \mathrm{~J}$. AM. MED. Ass'N 870, 874 (1998) (describing reduced support for replacing coroners with medical examiners as worrisome).

8. For example, Randy Hanzlick has argued that "[d]eath investigations may involve complex medical issues which require physician interpretation and judgment. Therefore, it is important that these death investigation systems - whether coroner or medical examiner-include appropriately educated and trained physicians with special expertise in the subject matter." Hanzlick, supra note 7, at 279. Similarly, in 2015, the National Commission on Forensic Science requested that "the Attorney General of the United States approve a policy that recommends that all offices, facilities, or institutions performing medicolegal death investigation activities be accredited by the year 2020," and stated that "[o]f the estimated 2,366 medicolegal death investigation offices in the United States, less than 100 are accredited by either the National Association of Medical Examiners (NAME) or the International Association of Coroners and Medical Examiners (IAC\&ME)." NAT'L COMM'N ON Forensic SCI., DeP'T OF JUsTiCe, Accreditation of Medicolegal Death Investigation Offices 1 (2015), https://www.justice.gov/sites/default/files/ncfs/pages/attachments/2015/01/21/mdiaccreditationfin al.pdf [https://perma.cc/EV5E-KDVH].

9. E.g., Lee Epstein, Electoral Benefits: The Assault on the Assaulters of Judicial Elections, 96 JUdiCATURE 218, 219-21 (2013); Charles Gardner Geyh, Why Judicial Elections Stink, 64 OHIO ST. L.J. 43, 51 (2003); cf. Stephen J. Choi, G. Mitu Gulati \& Eric A. Posner, Professionals or Politicians: The Uncertain Empirical Case for an Elected Rather than Appointed Judiciary, $26 \mathrm{~J}$. L. ECON. \& ORG. 290 (2010) (testing the conventional wisdom that appointed judges are more independent than, and therefore superior to, elected judges). 
that they are going to do that more when elections approach. ${ }^{10}$ On the flip side, the professionals - the ones who have job security and cannot be removed except for extreme misbehavior-have little incentive to consider the preferences and needs of those who they are supposed to be serving. They are going to be more independent, which does not always result in what is good for society; they may use that independence to shirk their job obligations. These tensions between independence and responsiveness are familiar, and much debated, in the judicial context. Less attention has been paid to whether it is better to have professionals or politicians populate other key roles in the legal system, such as prosecutors, defense lawyers, and sheriffs, in addition to death examiners. We hope to add insight into this question through an examination of death examiners.

Many of us are familiar with death examiners only through television, from shows like CSI, Bones, and Body of Proof. There, the characters tend to be super doctors with unlimited resources to do whatever tests they want. Reality is different. The systems for death examination vary considerably across the fifty states. As noted earlier, in some states, a high school diploma suffices as the qualification to run for election to be a coroner (the politicians). ${ }^{11}$ In North Carolina, until 1967, all that coroner candidates needed to do to be qualified was "to declare they had not denied the being of Almighty God or participated in a duel."12 In other states, doctors are in charge of the investigations, but even here there appear to be issues; some doctors are not pathologists, while others are pathologists who never passed their board exams.

Death examiners do the first evaluation of a dead body and determine whether further investigation into the cause of death is warranted. This decision regarding whether to do additional investigation (an autopsy) and the quality of the subsequent investigation that is done if an autopsy is ordered can be important. The paradigm case is the circumstance where an otherwise healthy person dies suddenly in a prison lockup. The death examiner will be the one who typically has to make the decision regarding whether the

10. Epstein, supra note 9, at 220.

11. See, e.g., Randy Hanzlick, Overview of the Medicolegal Death Investigation System in the United States, in MEDICOLEGAL WORKSHOP SUMMARY, supra note 6, at 7, 9-10. For an example of the requirements necessary to become a coroner, see Role of the Medical Examiner, FoRENSIC SCI., http://lorpub.gadoe.org/State\%20of\%20Georgia/GAVS\%20Shared/Science/ForensicScience_Autop syRoleMedicalExaminer_SHARED/ForensicScience_AutopsyRoleMedicalExaminer_SHARED5.h tml (last updated Sept. 1, 2015) [https://perma.cc/7S9R-43MS] (cataloging coroner eligibility requirements mandated by law in the state of Georgia).

12. Bernard HirschHorn, Democracy Reformed: Richard Spencer Childs AND His Fight FOR BETTER GOVERNMENT 156 (1997) (internal quotation marks omitted). 
circumstances were suspicious enough to warrant an autopsy and, further, what level of resources should be expended in doing the autopsy (additional tests, etc.). If done promptly and properly, an autopsy might, for example, show that the prisoner was beaten recently, leading to liability for the state and a political scandal. If not investigated quickly, the evidence might deteriorate and, indeed, be completely destroyed by a cremation. The question then is whether having a politician who faces regular elections, as compared to a professional with job security, in charge of the death examination process is more or less likely to result in a proper investigation of what happened. In cases where the death examination officer is a politician with close ties to the local police, there might be an incentive to avoid doing too much investigation. ${ }^{13} \mathrm{In}$ contrast, one might also imagine that officials who face regular elections would be under constant pressure to perform wellparticularly if the local press was monitoring and reporting on suspicious events-and less susceptible to outside influence such as bribes or the desire to curry favor with the local police. The point is that, assuming we think that a process should be put in place such that suspicious deaths are investigated-and particularly so when they involve potential abuses by state actors-it is not clear whether elected politicians or appointed medical professionals would do better.

Autopsies can also yield useful information in other contexts, especially in terms of revealing undiagnosed illnesses and nonobvious errors in medical treatments. ${ }^{14}$ There are significant public health benefits to knowing why people are dying; autopsies can reveal spreading diseases that public health officials might not have otherwise caught. ${ }^{15}$ Autopsies, however, require the expenditure of resources. Even basic autopsies cost over $\$ 1,000 .{ }^{16}$ And that number increases further if the doctors hired to do the investigations are themselves

13. See, e.g., A.C. Thompson et al., In New Orleans, Uncovering Errors and Oversights, NPR (Feb. 1, 2011, 12:00 AM), http://www.npr.org/2011/02/01/133301618/in-new-orleans-uncoveringerrors-and-oversights [https://perma.cc/E7TJ-KXQS] (discussing alleged systemic problems in autopsies in New Orleans); see also Adriane Quinlan, After 40 Years in Office, New Orleans Coroner Frank Minyard is Moving On, TIMEs-PiCAYUne (May 2, 2014, 12:47 PM), http://www.nola.com/health/index.ssf/2014/05/after_40_years_in_office_new_o.html

[https://perma.cc/8CCP-HTN8] (spotlighting the elected coroner at the center of the controversy in New Orleans' autopsies).

14. Marshall Allen, Without Autopsies, Hospitals Bury Their Mistakes, ProPublicA (Dec. 15, 2011, 12:36 PM), https://www.propublica.org/article/without-autopsies-hospitals-bury-theirmistakes [https://perma.cc/YGR8-W2LT] (contending that fewer autopsies in recent years have allowed medical diagnostic errors to go undiscovered).

15. See Randy Hanzlick, Medical Examiners, Coroners, and Public Health: A Review and Update, 130 ARChives PATHOLOGY \& LABORATORY MED. 1274, 1276-78 (2006) (cataloging the public health benefits of autopsies).

16. Allen, supra note 14 . 
expensive and tend to demand expensive tests. A professional, as contrasted with a politician, might not be terribly concerned about spending taxpayer funds on autopsies which, to the extent they unearth a scandal involving state abuse, might result in taxpayers having to pay out even more to compensate for the abuse. Will death examiners who are elected to their positions-and thus are more responsive to taxpayer concerns-be more sensitive to costs and therefore be in the best position to make this tradeoff?

Our initial goal with this project was to test the difference in performance between offices run by appointed medical professionals or elected coroners (who may not even have a basic medical degree, let alone be board certified in pathology). As noted, the strong sentiment in the literature is that medical professionals do a better job than local politicians. ${ }^{17}$ This seemed plausible to us, but there is almost no empirical evidence that supports that claim. ${ }^{18}$ And there are enough scandals involving the medical professionals who do death examinations to at least raise the question that they are not always doing the best job. ${ }^{19}$

Our starting hypothesis is that, all else equal, offices run by professional medical examiners would make fewer errors and be less likely to be beholden to local political interests than coroners. In the alternative, the desire for professional qualifications may be overdone and, worse, driven by some combination of elitism and self-interest of the medical profession that has a strong influence at institutions, such as the National Academy of Sciences, that have been pushing for the

17. E.g., JENTZEN, supra note 6; Hanzlick, supra note 7.

18. See infra notes 25-30 and accompanying text (discussing the NPR and ProPublica studies).

19. E.g., Radley Balko, The Fifth Circuit Turns Its Back on a Huge Forensics Scandal in Mississippi, WASH. POST (Feb. 28, 2014), https://www.washingtonpost.com/news/thewatch/wp/2014/02/28/the-fifth-circuit-turns-its-back-on-a-huge-forensics-scandal-in-

mississippi/?utm_term=.38ac0167c996 [https://perma.cc/DQU4-CF2E] (discussing controversy in Mississippi over a medical examiner's practices); Walt Bogdanich, A Mother's Death, a Botched Inquiry and a Sheriff at War, N.Y. TIMES (June 17, 2017), https://www.nytimes.com/2017/06/17/us/michelle-oconnell-jeremy-banks.html?_r=1

[https://perma.cc/56CY-Y7FP] (detailing a death investigation scandal in Florida); Conor Friedersdorf, CSI Is a Lie, ATLANTIC (Apr. 20, 2015), https://www.theatlantic.com/politics/archive/2015/04/csi-is-a-lie/390897/ [https://perma.cc/KW98GCA7] (highlighting concerns about forensic and state crime lab systems generally); Jenifer McKim, Child Deaths Go Unsolved as Autopsies Fall Behind, Bos. Globe (Nov. 29, 2015), https://www.bostonglobe.com/metro/2015/11/28/many-investigations-into-massachusetts-childabuse-deaths-remain-limbo-for-years/e4qO9xOmlthllM8PV2rXBN/story.html

[https://perma.cc/6GUL-YWJU] (investigating backlog of autopsies in Massachusetts); This Time, Fix N.C. Medical Examiner System, CHARLOTTE OBSERver (Apr. 7, 2015, 4:40 PM), http://www.charlotteobserver.com/opinion/editorials/article17747501.html

[https://perma.cc/B54A-6ZE6] (discussing the flaws of the death investigation system in North Carolina). 
professionalization of the death examiner position. ${ }^{20}$ Maybe it is not that difficult to determine whether the circumstances of death are suspicious and warrant further investigation by a medical professional.

In what follows, we report on our findings. We should state at the outset though that our findings are limited by the sparseness of the available data. To the extent that we have persuaded readers that the underlying question of whether coroners or professional medical examiners perform better is an important one, our bottom line is that there is a desperate need for good data.

We focus initially on two measures of performance relevant for autopsies. First, we look at the number of death examiner offices in a state that are accredited by the National Association of Medical Examiners ("NAME"). ${ }^{21}$ We conjecture that accreditation by the NAME is a proxy for the (high) quality of the death examinations that take place in the state. The greater the number of accredited death examiner offices in the state (which can include either a coroner or a professional medical examiner), the greater is the overall quality of death examinations in the state. Second, we look at the number of litigation events related to misconduct in an autopsy under state law. If the death examiner does a poor job, we expect that the chance of litigation arising from the low-quality autopsy or decision not to do an autopsy will be high.

We next look to the question of why any rational state would have anything but board-certified pathologists doing death investigations. A century ago, almost all states relied on nonmedical professionals-coroners - to conduct medical examinations of the deceased. Historically, coroners often served a nonmedical function, locating and determining the legal ownership of any found treasure trove. Commencing about a century ago, states began to shift toward

20. In 2009, the National Academy of Sciences called for a move away from allowing lay coroners to sign death certificates. See CoMm. ON IDENTIFYING THE NEEDs of THE ForEnsiC SCI. CMty., NAT'L ACAD. of Scis., Strengthening Forensic Science in the United States: A PATH FORWARD 241-68 (2009), https://www.ncjrs.gov/pdffiles1/nij/grants/228091.pdf [https://perma.cc/QWR5-6RFL] (calling for the elimination of the coroner system).

21. The National Association of Medical Examiners

is the national professional organization of physician medical examiners, medicolegal death investigators and death investigation system administrators who perform the official duties of the medicolegal investigation of deaths of public interest in the United States. NAME was founded in 1966 with the dual purposes of fostering the professional growth of physician death investigators and disseminating the professional and technical information vital to the continuing improvement of the medical investigation of violent, suspicious and unusual deaths.

About NAME, NAT'L ASS'N MED. https://netforum.avectra.com/eweb/DynamicPage.aspx?Site=NAME\&WebCode=AboutNAME (last visited Sept. 21, 2017) [https://perma.cc/SD6N-Q2MY]. 
professional medical examiners. While the majority of states today either exclusively or partially rely on medical examiners, a number of states continue to rely solely on the coroner system. ${ }^{22}$ What explains the persistence of coroners in these states?

There are a number of potential answers. First, it may simply be local corruption. Politicians may use lower visibility positions to reward supporters or friends or family of a supporter. The little-followed coroner position may be an example of the type of position that is given as a reward. Politicians may either appoint a supporter to the coroner position or nominate the supporter as the party candidate in an elected coroner position. We predict that states in which there is greater corruption and a greater history of political patronage affecting the staffing of governmental positions will be more likely to have retained the coroner position and resisted the trend toward professional medical examiners.

Second, some states have a long tradition of not deferring to expertise but instead relying on more direct democracy to fill important governmental positions. Even if some degree of expertise is sacrificed, such states gain to the extent elected officials are more responsive to the preferences of citizens and reflect a preference in such states for direct democracy. We predict that those states that demonstrate a preference for direct democracy, in particular, those states with an elected judiciary (whether partisan or nonpartisan elections), will be more likely to also stay with the coroner system.

In what follows, we briefly describe the scarce literature that compares coroner and medical examiner systems and then move to some basic empirical tests using the available data. While the underlying questions about system design are important and interesting, the available data is so poor that it is difficult to come to informed conclusions.

\section{BACKGROUND}

The legal literature on death examinations is thin. One student note, from over a decade ago, noted the enormous variation across death examination systems in the United States, focusing in particular on the

22. Graphics: How Is Death Investigated in Your State?, NPR (Feb. 1, 2011, 12:00 AM), http://www.npr.org/2011/02/03/131242432/graphics-how-is-death-investigated-in-your-state [https://perma.cc/8AJF-S4SG] (displaying graphically the death investigation systems in each state). 
differences in required qualifications across the systems. ${ }^{23}$ There are a handful of other articles discussing the value of resuscitating the common law procedure of death inquests (grand jury-like procedures to investigate deaths in certain circumstances), still used in places like Vermont and Missouri. The legal literature on death examinations ends there. ${ }^{24}$

There has been slightly more interest in death investigations in medical-academic communities and in the popular media. Most relevant are a series of broadcasts, articles, and reports that NPR produced between 2011 and 2013, entitled Post-Mortem: Death Investigation in America. ${ }^{25}$ In partnership with ProPublica, NPR conducted a quantitative study of coroner/medical examiner offices across the United States. ${ }^{26}$ The study attempted to break down death investigations by the kind of professional performing each investigation and also sought to identify how many autopsies were performed versus how many autopsies might be expected. ${ }^{27}$ One can quibble over whether the number of autopsies performed is a good measure of the quality of a death examination system-after all, the quality of the autopsies is a crucial variable here. That said, the gap between expected autopsies and actual autopsies, if it could be constructed credibly, would give us a good sense of the variation across systems in terms of whether investigations were even occurring. Unfortunately, extending NPR's research effort is not easy-autopsy data is not readily available and has to be collected by contacting individual death examiner offices. Of particular relevance to us, NPR's data was collected on very few of the coroner-only states, which means that the most important comparison of how coroner-only states were performing against medical examiner states could not be done in a meaningful fashion. The bottom line of the

23. Andrea R. Tischler, Note, Speaking for the Dead: A Call for Nationwide Coroner Reform, 33 Sw. U. L. REV. 553, 558 (2004) (highlighting the divergence in eligibility requirements between states).

24. Paul MacMahon, The Inquest and the Virtues of Soft Adjudication, 33 YALE L. \& PoL'Y REv. 275, 281 (2015) (discussing death inquests generally); H. Morley Swingle, Coroner's Inquests in Missouri: Modern Usage of the Hue and Cry, 63 J. Mo. B. 80, 83 (2007) (discussing death investigations in Missouri); Paul S. Gillies, When Inquests Were Inquisitions, VT. B.J., Fall 2015, at 10, 10-15 (discussing death investigations in Vermont).

25. Post Mortem: Death Investigation in America, NPR, http://www.npr.org/series/ 133208980/post-mortem-death-investigation-in-america (last updated Jan. 4, 2013) [https://perma.cc/RVW4-XCMM].

26. Autopsy Data, NPR (Feb. 1, 2011, 4:02 PM), http://www.npr.org/2011/02/02/ 133381758/autopsy-data [https://perma.cc/H2Q9-A84Y].

27. Id. The expected autopsy rate was computed based on the CDC mortality data on the relationship between autopsy rate and the homicide and unintentional-death rate in an area. Id.; see also Krista Kjellman Schmidt, About Our Autopsy Data, ProPubliCA (Feb. 1, 2011, 12:00 AM), https://www.propublica.org/article/about-our-autopsy-data (explaining calculations in greater detail). 
NPR study was that the system as a whole was woeful, with no clear coroner versus medical examiner result. ${ }^{28}$

ProPublica also published a series of articles illustrating the problems with death investigations. ${ }^{29}$ These articles highlight cases where the death investigation system has failed and point to the lack of uniform training and standards, as well as a national shortage of qualified pathologists to properly investigate each death that merits such an investigation. ${ }^{30}$ There are also examples in popular news media of botched autopsies or entire coroner/medical examiner offices run astray. ${ }^{31}$ These articles tend to highlight particularized and especially egregious examples of poor coroner/medical examiner performance without examining pervasive, systemic failures of the current death investigation system. ${ }^{32}$ There are still other popular news stories covering more general failures of state crime labs. ${ }^{33}$ Overall though, there is little in the way of systematic data collection or analysis about the death examination system.

\section{DATA}

To examine the coroner versus medical examiner question, we had to first construct measures of quality that could be used to compare the two systems at the state level. A more fine-tuned analysis would examine matters at the county level, but for this exploratory examination, we limited our analysis to the state level. Not being experts, we spoke to a number of medical examiners and coroners (some

28. See Map: Death in America, PBS, http://www.pbs.org/wgbh/pages/frontline/postmortem/map-death-in-america/ (last visited Sept. 21, 2017) [https://perma.cc/C7BJ-G9ZK] (detailing geographically the varying systems of death investigations in each state).

29. E.g., A.C. Thompson et al., Real CSI: Patchy U.S. Death Investigations Put the Living at Risk, ScI. AM. (Feb. 1, 2011), https://www.scientificamerican.com/article/patchy-us-deathinvestigations/ [https://perma.cc/3RUT-FCU6] (highlighting shortcomings in the current coroner system).

30. See id.

31. See, e.g., Jessica Pishko, Angela Corey's Forgetful Medical Examiner, NATion (Aug. 30, 2016), https://www.thenation.com/article/angela-coreys-forgetful-medical-examiner/ [https://perma.cc/PA6Z-GMMW] (documenting allegations that the dementia and problematic practices of a former medical examiner were intentionally overlooked by a former Florida state attorney).

32. See, e.g., Jeff Marcu, Chief Medical Examiner Says She Found Malpractice When She

Took over Office, FirstConstNews.com (Apr. 13, 2012, 8:08 PM), http://downtownjax.firstcoastnews.com/news/news/77084-chief-medical-examiner-says-she-foundmalpractice-when-she-took-over-office [https://perma.cc/6NYJ-85RK] (recounting systemic issues within county medical examiner's office).

33. See, e.g., Dahlia Lithwick, Crime Lab Scandals Just Keep Getting Worse, Slate (Oct. 29, 2015, 5:21 AM), http://www.slate.com/articles/news_and_politics/crime/2015/10/massachusetts _crime_lab_scandal_worsens_dookhan_and_farak.html [https://perma.cc/5NXY-JQBN] (highlighting egregious misconduct by chemist in state drug lab). 
of the latter were also lawyers and judges) about what kinds of measures they would find to be credible indicators. Considering the caveat that they all warned us that data would be difficult to obtain, we posit that the following could act as proxies for death examination quality.

$>$ Qualifications: Employees with better qualifications presumably do a better job. In theory, this measure could look at whether the pathologists doing the autopsies are board certified. Alternatively, this measure could focus on the fraction of the pathologists in that state who are board certified or whether the local offices are accredited by a credible national or international agency.

$>$ Litigation: Better run offices presumably have fewer lawsuits brought against them relating to autopsieseither regarding the quality of a performed autopsy or the decision whether to perform an autopsy. One indicator of quality might be the number of lawsuits brought against death examiners in a state alleging errors in the death examination process (adjusted for the size of the population in the state) for a particular time period.

$>$ Scandals: Even good offices make errors. But large and systemic problems - the kinds of events that make for news stories-are likely a sign of dysfunction. A possible indicator of office quality, therefore, is the number of major news stories in a particular time period regarding systemic problems in a local death examiner office. ${ }^{34}$

$>$ Scope: Some offices investigate deaths more extensively than others - that is, their threshold for what deaths are deemed suspicious is lower. Possible measures of this are the yearly expenditures of the office and the fraction of possibly suspicious deaths for which autopsies are actually conducted.

One could imagine even more intricate measures that would address specific concerns about having political actors running death

34. An alternate source of information here, which we are considering for future research, is ethics complaints against public officials. Most states have procedures that allow for complaints to be made against public officials, and there is often information about the substance of the complaints. See, e.g., Forrest Berkshire, Deputy Coroner Resigns After Ethics Complaint Filed, KY. STANDARD (May 1, 2014, 8:32 AM), http://www.kystandard.com/content/deputy-coroner-resignsafter-ethics-complaint-filed [https://perma.cc/556H-K7RU] (detailing basis for ethics complaint against coroner). 
examinations, such as the fraction of suspicious prison deaths that do not get investigated. One might also look at the fraction of initial autopsies where a second one-requested by family members or performed by an outside agency - concludes with a different result. We decided for the purpose of this Article to focus on the basic measures.

Of the four measures, we made progress in obtaining information related to the first two proxies for death examination quality listed above: measures of whether the offices in the state had been certified by a credible national agency and numbers of litigation events. We were unable to generate measures related to the latter two proxies. Systematic measures of autopsy-related scandals, based on a search from a subset of national news outlets, turned out to be difficult. Many stories relating to autopsy scandals do not make it to the national news, and comparing news stories from local outlets that vary enormously in quality and coverage is difficult. Finally, the scope measure was one that we were initially hoping to use based on the methodology used in the NPR and ProPublica study (including in particular the difference between actual numbers of autopsies and expected numbers of autopsies). However, it turned out to be difficult to obtain data on either the numbers of autopsies or the budgets of individual offices. There are no reliable published sources, and our attempts at contacting individual offices for information were unsuccessful. For future research, we hope to set up a more extensive research team to start collecting the kind of ground level data that we were unable to obtain in our initial attempts.

We obtained data on whether a state only has coroners (Coroner Only) or has either a mix of medical examiners and coroners or only medical examiners (Partial or Medical Examiner Only) from the work of Randy Hanzlick, the chief medical examiner of Fulton County (Georgia). ${ }^{35}$ We also obtained data on the number of medical examiner offices in a state that are accredited by the NAME, as measured in 2016 . We compared states directly based on NAME. Because the population of a state may affect the NAME number, we also compared states based on the NAME per million people in the population in 2010.

We obtained data on the number of autopsy-related litigation cases involving allegations of misconduct from January 1, 1950, to February 1, 2017, through searches on Westlaw and Lexis. Our search uncovered only those cases with opinions that appear in Westlaw or Lexis, so the search is likely underinclusive of all autopsy-related litigation. In addition, given that most of the public officials being sued

35. Hanzlick \& Combs, supra note 7, at 871. 
will have some kind of qualified immunity from suit, ${ }^{36}$ some of the claims may be getting dismissed early in the litigation process on immunity grounds and, as a result, may not appear in Westlaw or Lexis.

Nonetheless, to the extent that the number of cases without opinions is not correlated with Coroner Only compared with Partial or Medical Examiner Only states, our comparison provides an accurate depiction of the relative performance of Coroner Only and Partial or Medical Examiner Only states. Because the amount of autopsy litigation is correlated with the number of deaths in a state (which in turn is correlated with state population), we scale the number of autopsy litigation cases by the population of each state measured in 1950 (Autopsy litigation per million population in 1950).

\section{ANALYSIS}

As noted above, the ProPublica/NPR study collected data on a variable - the abnormal autopsy rate - that we thought would be a good preliminary indicator on the question we were interested in investigating. However, as mentioned above, the study did not collect data on enough of the Coroner Only states to provide meaningful evidence of the difference. Still, we report our analysis of their data to provide a sense of the direction in which their results point.

Figure 1 reports a comparison of abnormal autopsy rates, defined as the difference between actual autopsy rates and expected rates, for Coroner Only states, states using a mix of the Coroner and Medical Examiner systems, and states using the Medical Examiner system only. The NPR website explains:

The autopsy rate is calculated based on autopsies per 100,000 deaths. Then, using the CDC mortality data, ProPublica looked at the relationship between the autopsy rate and the rates of unintentional deaths and homicides. They found that the higher the homicide and unintentional-death rate in an area, the higher the autopsy rate tends to be. They used this relationship to compute an expected autopsy rate and then compared the expected autopsy rate and the actual autopsy rate to see whether counties and states performed fewer, more than or the expected number of autopsies, given their rates of unintentional deaths and homicides. ${ }^{37}$

The bar graphs in Figure 1 show that the gap between autopsy and expected autopsy rates for Medical Examiner Only states is different from states with Partial systems (termed "Mix" in the Figure) and from states with Coroner Only systems. And, while the differences

36. See, e.g., Waeschle v. Dragovic, 576 F.3d 539, 543-44 (6th Cir. 2009) (discussing a government official's qualified immunity defense); see also WASH. REV. CODE § 68.50.015 (2017) (codifying qualified immunity defense for coroners and medical examiners).

37. Autopsy Data, supra note 26. 
are not statistically significant, Figure 1 paints a distinct picture: other things equal, medical examiners perform more autopsies than coroners compared with the number of expected autopsies.

Figure 1: AbNoRMAl Autopsy RATE (NPR/ProPubliCA 2007 DATA)

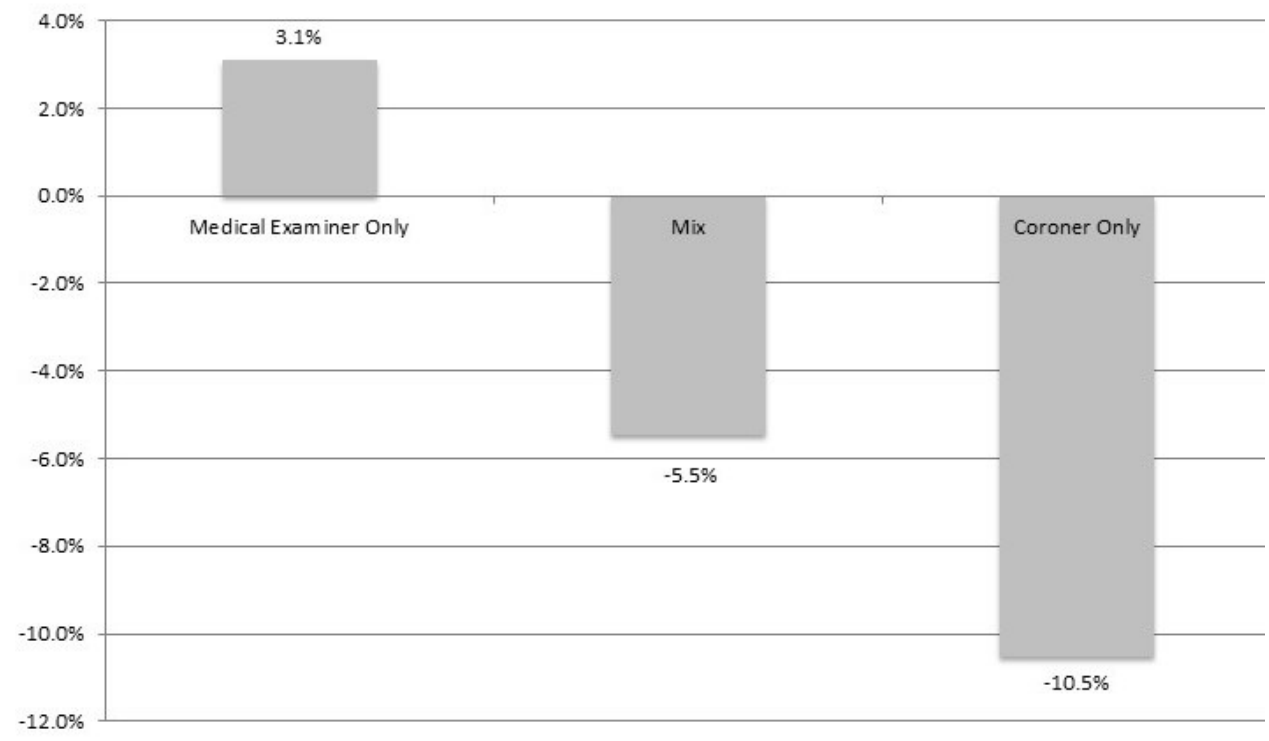

Source: Autopsy Data, NPR (Feb. 1, 2011, 4:02 $\quad$ PM) http://www.npr.org/2011/02/02/133381758/autopsy-data [https://perma.cc/H2Q9A84Y].

Next, we move to the data we collected on accreditation and litigation. Table 1 reports on the comparison between Partial or Medical Examiner Only states and Coroner Only states. For purposes of our binary comparisons, we group Partial and Medical Examiner Only states to test whether states that have at least some use of medical examiners (and thus at some point experienced a decision to implement medical examiners) differ from states that continue to use only coroners. 
TABLE 1: STATE COMPARISON FOR AUTOPSY QUALITY

\begin{tabular}{llll}
\hline & $\begin{array}{l}\text { Partial or } \\
\text { Medical } \\
\text { Examiner Only } \\
\text { State }\end{array}$ & $\begin{array}{l}\text { Coroner } \\
\text { Only } \\
\text { State }\end{array}$ & $\begin{array}{l}\boldsymbol{p} \text {-value of } \\
\text { Test of } \\
\text { Difference }\end{array}$ \\
\hline $\begin{array}{l}\text { Number of NAME Accredited } \\
\text { Offices in 2016 }\end{array}$ & 3.051 & 1.273 & 0.077 \\
\hline
\end{tabular}

$\begin{aligned} & \text { Number of NAME Accredited } \\ & \text { Offices in 2016 per Million }\end{aligned}$
Population*

$\begin{array}{llll}\text { Autopsy Litigation from } 1950 & 4.285 & 10.010 & 0.060\end{array}$ to 2017 per Million

Population**

*For the Number of NAME Accredited Offices in 2016 per Million Population measure, we used state population data from 2010.

**For the Autopsy Litigation from 1950 to 2017 per Million Population measure, we used state population data from 1950.

As we observed with the ProPublica autopsy data, under each of our measures for the quality of medical examinations, we find evidence that coroners perform poorly compared with professional medical examiners. Coroners are correlated with both fewer absolute numbers of accredited medical examiner offices as well as fewer accredited offices per million in population. The difference between Coroner Only and Partial or Medical Examiner Only states is significant at the 10\% level for the absolute NAME measure. The difference for the NAME per million population measure is significant at the $11.1 \%$ level, just beyond conventional levels of statistical significance. Likewise, we find that Coroner Only states experience higher litigation rates involving autopsies compared with Partial or Medical Examiner Only states. This difference is significant at the $10 \%$ level.

We next look to gain traction on the question of why a state might choose to stay with a coroner system. Specifically, we look to examine whether states that remain exclusively with the coroner system do so because of corruption or out of a preference for direct democracy, even at the expense of medical examination quality. As a measure of corruption, we utilize the ranking of states from the Center 
for Public Integrity in 2015. ${ }^{38}$ The Center for Public Integrity gives each state a corruption grade based on its assessment of the state along a number of categories including political financing, electoral oversight, lobbying disclosure, executive accountability, legislative accountability, and judicial accountability, among other categories. We focus in particular on those states that earned an "F" grade in 2015 , accounting for eleven of the fifty states. Table 2 reports on the comparison of Coroner Only and Partial or Medical Examiner Only states based on the incidence of " $F$ " corruption grades.

\section{TABLE 2: STATE COMPARISON OF CORRUPTION SCORE}

\begin{tabular}{lccc}
\hline & $\begin{array}{l}\text { Partial or Medical } \\
\text { Examiner Only State }\end{array}$ & $\begin{array}{l}\text { Coroner } \\
\text { Only State }\end{array}$ & $\begin{array}{l}\boldsymbol{p} \text {-value of Test of } \\
\text { Difference }\end{array}$ \\
\hline $\begin{array}{l}\text { State } \\
\text { Corruption } \\
\text { "F" Score in }\end{array}$ & 0.150 & 0.500 & 0.016 \\
$\mathbf{2 0 1 5}^{*}$ & & & \\
\hline
\end{tabular}

*State corruption score from the Center for Public Integrity 2015 state rankings.

Note from Table 2 that half of the Coroner Only states received an "F" grade in 2015 while only $15 \%$ of the Partial or Medical Examiner Only states received an " $F$ " grade. This difference is significant at the $1.6 \%$ confidence level. Put differently, the states using the coroner system are among the most corrupt in terms of government officials.

An alternative story for the use of coroner systems is that the populations for some states might have a strong preference for direct democracy. As a multivariate test of when a state shifted to either a partial or medical examiner only system, we estimated a series of Cox proportional hazard models for the first adoption of a professional medical examiner in a state, looking at state-year level data. The Cox proportional hazard model is a type of statistical survival model that relates the time until a specified event to various independent variables that may affect the amount of time until the event (such as the state population over time). For the independent variables in the Cox proportional hazards model, we include the log of the state population determined by the most recent census (so for 1964 we used the 1960 state population), as well as indicator variables for the judicial selection regime for state supreme court judges as a proxy for the state's

38. Yue Qiu et al., How Does Your State Rank for Integrity?, CTR. FOR PUB. INTEGRITY (Nov. 9, 2015, 12:04 AM), https://www.publicintegrity.org/2015/11/09/18822/how-does-your-state-rankintegrity [https://perma.cc/V2NZ-L2SZ]. 
preference for direct democracy. We code the judicial selection systems in terms of four broad categories of systems that are frequently used in the literature comparing the different systems: Appointment, Merit Selection, Partisan Election, and Nonpartisan Election. ${ }^{39}$ We use Nonpartisan Election for state supreme court judges as the base category. Model 1 of Table 3 reports the results. ${ }^{40}$

TABLE 3: HAZARD MODEL OF ADOPTION OF MEDICAL EXAMINER

\begin{tabular}{lccc}
\hline & Model 1 & Model 2 & Model 3 \\
\hline Ln (state & 1.205 & 1.235 & 1.305 \\
population) & $(1.07)$ & $(1.11)$ & $(1.21)$ \\
Partisan Election & 2.079 & - & 2.064 \\
& $(1.28)$ & - & $(1.24)$ \\
Merit Selection & $3.354^{*}$ & - & $3.375^{*}$ \\
& $(2.24)$ & - & $(2.01)$ \\
Appointment & $3.483^{*}$ & - & $3.517^{+}$ \\
& $(2.25)$ & - & $(1.82)$ \\
Northeast & - & 1.758 & \\
& - & $(1.07)$ & 1.277 \\
South & - & 2.087 & $(0.35)$ \\
& - & $(1.57)$ & 1.350 \\
West & - & 1.284 & $(0.59)$ \\
& - & $(0.44)$ & \\
& & & $(.657$ \\
$N$ & 2760 & 2760 & \\
pseudo $R^{2}$ & 0.040 & 0.023 & 2760 \\
Log likelihood & -121.4 & -123.7 & -121.0 \\
\hline
\end{tabular}

Exponentiated coefficients; $z$-statistics in parentheses; ${ }^{+} p<0.10,{ }^{*} p<0.05$.

In Model 1 of Table 3, note that the coefficients on Merit Selection and Appointment are both greater than one, indicating an increased probability of shifting to a professional medical examiner

39. These are explained in Choi, Gulati \& Posner, supra note 9, at 297.

40. As a historical matter, the choices of state judicial election systems have been far more stable than the choices about whether to use a coroner system. See id. at 303-04 (discussing the stability of the judicial selection systems). As a practical matter, the judicial regimes were almost all put in place prior to the shift toward a professional medical examiner system (and therefore may be treated as roughly exogenous for our purposes). According to Hanzlick and Combs, the shift toward the medical examiner system was occurring on a fairly steady basis from the $1880 \mathrm{~s}$ until roughly the 1980s, when it slowed down considerably. See Hanzlick \& Combs, supra note 7, at 872-73. 
compared with the base category of Nonpartisan Election states (significant at the $5 \%$ confidence level). This is consistent with a preference (as measured by the type of judicial selection system used) for direct democracy impacting how a state selects its coroners. Nonetheless, the differences between the coefficients for Partisan Election and Merit Selection and the coefficients for Partisan Election and Appointment are not significantly different from zero.

To test whether there is a geographic region effect, we remove the judge selection indicator variables and replace them with regional indicators for whether a state is a member of U.S. Census Region Northeast, South, or West, with the Midwest as the base category. Model 2 of Table 3 reports the results. None of the coefficients on the regional indicators are significantly different from zero. Thus, region itself does not explain the shift to a professional medical examiner system.

Lastly, Model 3 of Table 3 combines the indicator variables for the judge selection regime with the region indicator variables. As reported in Model 3, the indicator variables for the Merit Selection and Appointment regimes continue to be greater than one and significant, consistent with citizens from more election-focused states preferring to remain with the coroner system. However, as with Model 1, the differences between the coefficients for Partisan Election and Merit Selection and the coefficients for Partisan Election and Appointment are not significantly different from zero.

\section{CONCLUSION}

Despite the limited availability of data, we can make a few observations about coroner systems versus medical examiner ones. Generally speaking, the death examiner offices in coroner states perform fewer autopsies than they should, are less likely to be accredited by the major national organization, and generate greater amounts of litigation. Of these three measures that we report on, the accreditation number is perhaps the most meaningful. In theory, death examination offices run by politicians could do well on these scores, but our findings suggest that they do not. An alternative possibility, though, is that the accreditation system is run by the professional medical examiners and biased against the offices in coroner states.

The next question to ask is why states choose to remain with the coroner systems, despite the wide condemnation they have received. Two possibilities that we cannot dismiss are (a) that states with greater amounts of official corruption prefer elected officials doing death 
examinations, and (b) that these are states that, as a general matter, prefer direct democracy.

Our results do no more than begin to identify the differences between coroner and medical examiner systems in terms of quality. We hope to have shown, however, that it is worth investing in better data, so that scholars can begin to get some traction on answering these questions more thoroughly.

There are two lines of attack that could be usefully pursued. First, there is the cross-sectional data comparing states (and better, counties) in terms of the relative performances of their departments, controlling for variables that might capture local differences. Second, given that a number of states (and counties) have changed their systems in recent years-North Carolina, for example ${ }^{41}$ - scholars can now do case studies of the individual county systems and compare the before and after results of the change.

41. See Jon Evans, Senate Votes to Abolish Columbus County Coroner's Office, WECT (Apr. 19, 2017, 7:24 PM), http://www.wect.com/story/35193713/senate-votes-to-abolish-columbuscounty-coroners-office [https://perma.cc/9C8D-9SPF] (recording vote to abolish coroners' offices in multiple counties). 